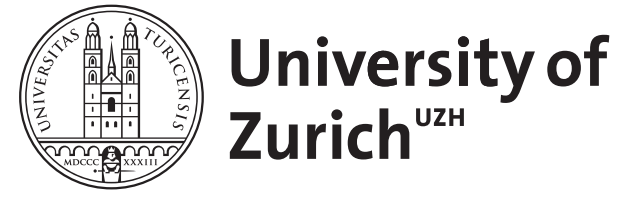
Archive

University of Zurich

University Library

Strickhofstrasse 39

CH-8057 Zurich

www.zora.uzh.ch

Year: 2013

Soil microbial diversity and agro-ecosystem functioning

van der Heijden, Marcel G A ; Wagg, Cameron

DOI: https://doi.org/10.1007/s11104-012-1545-4

Posted at the Zurich Open Repository and Archive, University of Zurich

ZORA URL: https://doi.org/10.5167/uzh-77626

Journal Article

Published Version

Originally published at:

van der Heijden, Marcel G A; Wagg, Cameron (2013). Soil microbial diversity and agro-ecosystem functioning. Plant and Soil, 363(1-2):1-5.

DOI: https://doi.org/10.1007/s11104-012-1545-4 


\title{
Soil microbial diversity and agro-ecosystem functioning
}

\author{
Marcel G. A. van der Heijden • Cameron Wagg
}

Received: 12 October 2012 / Accepted: 22 November 2012 /Published online: 8 December 2012

(C) Springer Science+Business Media Dordrecht 2012

Keywords Plant-soil feedback · Microbial diversity $\cdot$ Mycorrhiza $\cdot$ Agro-ecosystems $\cdot$ Species richness $\cdot$ Microbe $\cdot$ Ecosystem functioning

Soil microbes represent the unseen majority of life on Earth and are essential for the functioning of terrestrial ecosystems as they catalyze unique and indispensable transformations in the biogeochemical cycles of the biosphere (Whitman et al. 1998; van der Heijden et al. 2008). The significance of soil microbial diversity for the functioning of agricultural and natural ecosystems is still poorly understood and soil microbial communities can be considered as a black box (Kennedy and Smith 1995; Cortois and de Deyn 2012). Unraveling what soil microbes are doing in this black box has been identified as one of the major research areas in science.

Responsible Editor: Hans Lambers.

M. G. A. van der Heijden $(\bowtie) \cdot$ C. Wagg

Ecological Farming Systems, Agroscope Reckenholz-

Tänikon, Research Station ART,

Reckenholzstrasse 191,

8046 Zürich, Switzerland

e-mail: marcel.vanderheijden@art.admin.ch

M. G. A. van der Heijden

Institute of Evolutionary Biology and Environmental

Studies, University of Zürich,

Winterthurestrasse 190,

8057 Zürich, Switzerland

M. G. A. van der Heijden

Plant-Microbe Interactions, Institute of Environmental

Biology, Faculty of Science, Utrecht University,

3508 TC Utrecht, The Netherlands
An increasing number of studies demonstrate that agricultural practices, such as tree based intercropping (Lacombe et al. 2009; Bainard et al. 2012a, b), organic farming (Mäder et al. 2002; Bengtsson et al. 2005; Birkhofer et al. 2008; Verbruggen et al. 2010), reduced soil tillage (van Capelle et al. 2012), crop rotation (Altieri 1999; Cavagnaro and Martin 2011) and land use extensification (Postma-Blaauw et al. 2010; de Vries et al. 2012) have a positive impact on the abundance and richness of specific groups of soil organisms (e.g. arbuscular mycorrhizal fungi, earthworms) and on soil microbial diversity. Thus, by adapting farm management practices it is possible to favor recruitment of specific groups of soil organisms and enhance microbial diversity. As such, these findings make it possible to provide policy makers with recommendations on enhancing soil biodiversity in agricultural ecosystems. There are a number of mechanisms by which microbial diversity can support agro-ecosystem functioning and particular ecosystem functions such as plant productivity and decomposition. For instance, microbes can form "consortia" that enhance plant productivity (e.g. when different microbes provide different limiting resources to plants) or decomposition (e.g. when plant material is decomposed by specialized microbes with unique physiological properties that succeed each other). As a consequence, microbial diversity can promote ecosystem functioning. However, in other cases, the presence of key stone species (e.g. specific pathogens, nitrogen fixers) rather than diversity "per se" may determine agro-ecosystem functioning. Until now, it is still poorly understood, whether increased soil (microbial) diversity is beneficial for the functioning and sustainability of agricultural systems. 
In this issue (doi:10.1007/s11104-012-1321-5) an extensive study by Bainard and colleagues showed that things are certainly not simple. They used soil from conventional agricultural fields and from treebased intercropping systems as inoculum in a glasshouse bioassay and assessed the influence of soil biotic communities conditioned by these two different practices on three agricultural crops. In earlier work it was shown that soils from tree based intercropping systems had higher microbial diversity compared to conventionally managed soils (Lacombe et al. 2009; Bainard et al. 2012b). Hence, it was hypothesized that plants would benefit when inoculated with soils derived from tree based intercropping systems. In contrast to their hypothesis, there were no differences in effects between farming systems inocula. Moreover, two of the three crops (barley and canola) grew best in soil with sterilized inoculum. Thus, the results from this study do not indicate that plants benefit from increased microbial diversity (but see below). Instead, soil pathogens appeared to be a stronger driver of plant productivity than diversity for two of the investigated crop species in this study.

\section{Bottlenecks and advances}

The great difficulty in assessing the impact of soil microbes on plant productivity and ecosystem processes arises since microbial diversity and abundance cannot be easily manipulated without simultaneously changing other factors or organisms (Read 2002). Hence, it is a common approach to perform greenhouse experiments under controlled conditions in sterilized soil and add soil inoculum (Bainard et al. 2012a; Verbruggen et al. 2012; Maherali and Klironomos 2007; Wagg et al. 2011). By adding soil inoculum from fields with different microbial diversity it is subsequently possible to mimic differences in microbial communities under controlled conditions and test their impact on plants and ecosystems. When doing this, it is important to verify that differences in soil microbial diversity are responsible for observed effects. Consequently, it is required to demonstrate at the beginning and at the end of the experiment that soil microbial diversity differs among treatments. The experiments by Bainard et al. (2012a) were very large (750 pots) and hence such information was not presented (e.g. it is extremely laborious and financially demanding to determine microbial community composition of 750 pots). Thus, with the results presented it was not possible to draw firm conclusions. Further work is needed to test whether enhanced microbial diversity in tree-based intercropping systems can provide additional ecological services to these systems.

A number of recent developments provide opportunities for understanding how soil microbial communities influence the productivity and sustainability of cropping systems. First, costs for the molecular characterization of microbial communities (e.g. by high throughput sequencing) has declined considerably in recent years, making it now possible to characterize microbial communities for a larger number of samples. Second, fluxes of carbon and nutrients that are mediated by microbes can be measured with (stable) isotopes and related technology (such as stable isotope probing, see Vandenkoornhuyse et al. 2007; Kiers et al. 2011). With these techniques it is possible to show which microbes are active, thus providing mechanistic insights into the role of specific soil microbial communities in driving ecosystem functioning. Third, it is difficult to manipulate microbial diversity because many microbes readily disperse via air and water. As a consequence, microbes can easily contaminate pots and cause unwanted changes in experimental treatments. Hence, differences in the effects of microbial diversity at the start of the experiment may eventually disappear, especially if experiments are performed over longer periods of time. Recently, we developed an experimental system in which it is possible to manipulate microbial diversity in experimental ecosystems without contamination from the outside (Fig. 1). Such tools provide new avenues for testing whether soil microbial diversity influence ecosystem functioning and whether soils with high microbial diversity are important for sustaining agricultural production.

\section{Applicability of soil biodiversity research in Agro-Ecosystems}

The experiments by Bainard et al. also show that growth responses of crops in response to soil inoculation are variable. Barley and canola performed best in sterilized soil and these crops also did not benefit from the presence of arbuscular mycorrhizal (AM) fungi, soil fungi that facilitate plant growth by providing 
a

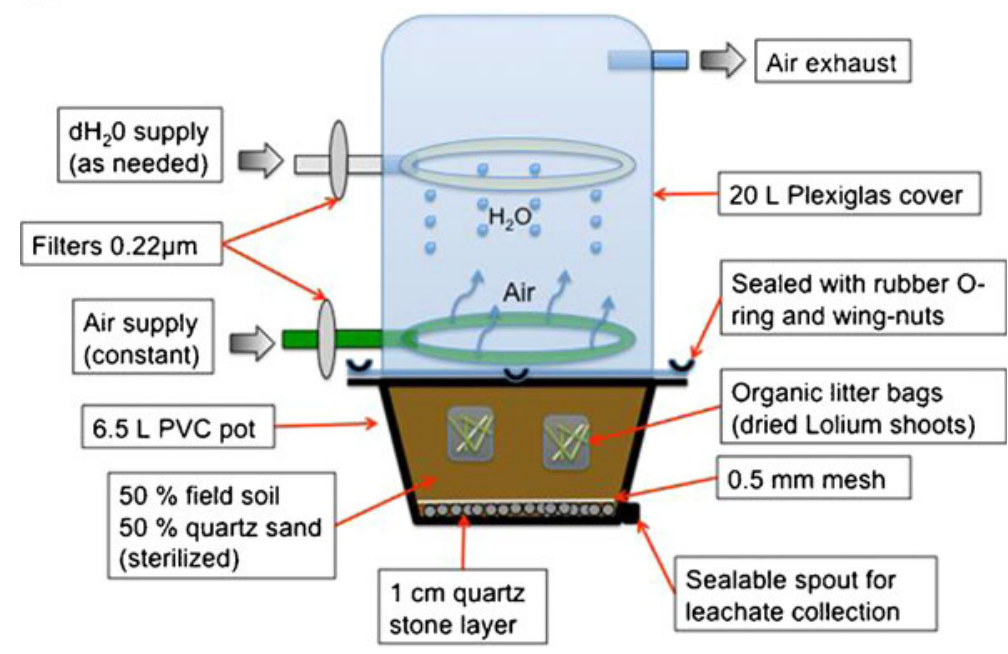

b

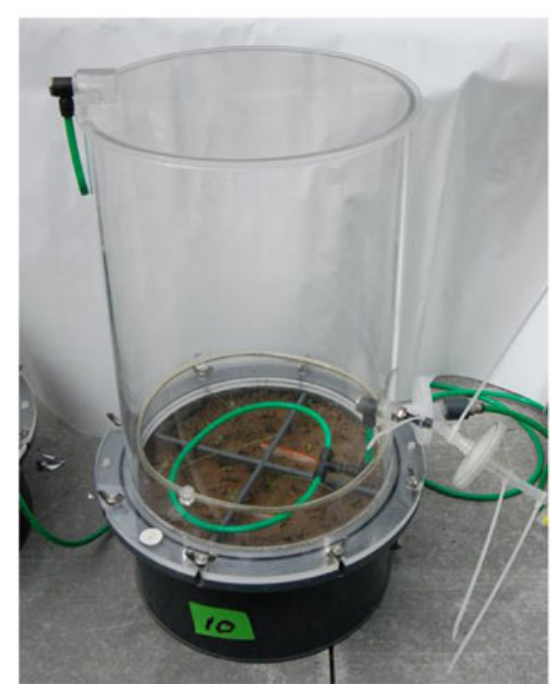

Fig. 1 Schematic draw (a) and photograph (b) of an experimental microcosm in which plants can be grown under controlled conditions without microbial contamination from the outside. In order to prevent microbial contamination, filling and planting of the microcosms needs to be performed in a laminar flow hood and all material needs to be sterilized or autoclaved before use. Moreover, during the growth period, incoming pressured air is filtered through a hydrophobic filter $(0.22 \mu \mathrm{m})$, while water/nutrient solution is filtered through a hydrophilic filter $(0.22 \mu \mathrm{m})$ to prevent contamination from the

plant inaccessible nutrients. This is perhaps to be expected since canola does not form AM fungal associations and a number of studies showed that barley does not necessarily benefit from AM fungi (e.g. Grace et al. 2009). Thus, it appears that the impact outside. Replicated microcosms can be inoculated with soil inoculum from different agricultural fields or microcosms can be inoculated with different (numbers of) microbes. Litter bags or hyphal compartments with labelled material $\left({ }^{13} \mathrm{C}\right.$ and or $\left.{ }^{15} \mathrm{~N}\right)$ can be added to the microcosms in order to test whether decomposition and/or nutrient uptake varies between microcosms with different microbial diversity treatments. ${ }^{13} \mathrm{CO} 2$ can be added to the microcosms (instead of pressured air) to trace the fate of assimilated C (to facilitate stable isotope probing). Microcosm Design: Marcel van der Heijden \& Susanne de Bruin

of plant antagonists of these crops on productivity was larger than those of beneficial soil organisms. In contrast, soybean grew equally well in sterilized and non-sterilized soil and in a second experiment, Bainard et al. demonstrate soybean performed better in 
pots inoculated with AM fungi, which is typical of most legumes. Thus, the effects of soil organisms on crops is driven by the species identity and plant functional group of the crop, making it difficult to make general recommendations about the benefits of soil microbial diversity in agro-ecosystems. Moreover, microbes not only influence plant productivity, but a wide range of ecosystem functions are affected by soil microbes that indirectly affect plant productivity, not only within a growing season but also over time (nutrient losses, nutrient cycling, soil structure stabilization etc. - see van der Heijden et al. 2008). Such indirect effects should not be overlooked when assessing the importance of soil microbial diversity.

In conclusion, there are now a wide range of studies describing how soil organisms and soil microbes respond to different agricultural practices. However, current understanding as to whether such changes in soil (microbial) diversity are beneficial for the functioning of agro-ecosystems is only in its infancy. Only a few studies, often theoretical or performed under highly controlled conditions with a particular group of microorganisms indicate that enhanced microbial diversity can indeed be beneficial by providing a number of ecosystem services (Brussaard et al. 2007; van der Heijden et al. 2008; Berendsen et al. 2012). The work by Bainard et al. provide new insights into the role of soil microbes in agro-ecosystem demonstrating negative soil feedback to be a strong mechanism. At the same time these authors also illustrate there remain many important questions to be addressed about the role of soil biodiversity in agroecosystems and its applicability.

\section{References}

Altieri MA (1999) The ecological role of biodiversity in agroecosystems. Agric Ecosyst Environ 74:19-31

Bainard LD, Koch AM, Gordon AM, Klironomos JN (2012a) Growth response of crops to soil microbial communities from conventional monocropping and tree-based intercropping systems. Plant and Soil (in press; doi:10.1007/s11104012-1321-5

Bainard LD, Koch AM, Gordon AM, Klironomos JN (2012b) Temporal and compositional differences of arbuscular mycorrhizal fungal communities in conventional monocropping and tree-based intercropping systems. Soil Biol Biochem 45:172-180

Bengtsson J, Ahnstrom J, Weibull AC (2005) The effects of organic agriculture on biodiversity and abundance: a metaanalysis. J Appl Ecol 42:261-269
Berendsen RL, Pieterse CMJ, Bakker PAHM (2012) The rhizosphere microbiome and plant health. Trends Plant Sci $17: 478-486$

Birkhofer K, Bezemer TM, Bloem J, Bonkowski M, Christensen S, Dubois D, Ekelund F, Fliessbach A, Gunst L, Hedlund K, Mader P, Mikola J, Robin C, Setala H, Tatin-Froux F, Van der Putten WH, Scheu S (2008) Long-term organic farming fosters below and aboveground biota: Implications for soil quality, biological control and productivity. Soil Biol Biochem 40:2297-2308

Brussaard L, de Ruiter PC, Brown GG (2007) Soil biodiversity for agricultural sustainability. Agric Ecosyst Environ 121:233-244

Cavagnaro TR, Martin AW (2011) Arbuscular mycorrhizas in southeastern Australian processing tomato farm soils. Plant Soil 340:327-336

Cortois R, De Deyn GB (2012) The curse of the black box. Plant Soil 350:27-33

de Vries FT, Liiri ME, Bjørnlund L, Bowker MA, Christensen S, Setälä HM, Bardgett RD (2012) Land use alters the resistance and resilience of soil food webs to drought. Nat Clim Chang 2:276-280

Grace EJ, Cotsaftis O, Tester M, Smith FA, Smith SE (2009) Arbusuclar mycorrhizal inhibition of growth in barley cannot be attributed to extent of colonization, fungal phosphorus uptake or effects on expression of plant phosphate transporter genes. New Phytol 181:938-949

Kennedy AC, Smith KL (1995) Soil microbial diversity and the sustainability of agricultural soils. Plant Soil 170:75-86

Kiers ET, Duhamel M, Beesetty Y, Mensah JA, Franken O, Verbruggen E, Fellbaum CR, Kowalchuk GA, Hart MM, Bago A, Palmer TM, West SA, Vandenkoornhuyse P, Jansa J, Bucking H (2011) Reciprocal rewards stabilize cooperation in the Mycorrhizal Symbiosis. Science 333:880-882

Lacombe S, Bradley RL, Hamel C, Beaulieu C (2009) Do treebased intercropping systems increase the diversity and stability of soil microbial communities? Agric Ecosyst Environ 131:25-31

Mäder P, Fliessbach A, Dubois D, Gunst L, Fried P, Niggli U (2002) Soil fertility and biodiversity in organic farming. Science 296:1694-1697

Maherali H, Klironomos JN (2007) Influence of phylogeny on fungal community assembly and ecosystem functioning. Science 316:1746-1748

Postma-Blaauw MB, de Goede RGM, Bloem J, Faber JH, Brussaard L (2010) Soil biota community structure and abundance under agricultural intensification and extensification. Ecology 91:460-473

Read DJ (2002) Towards ecological relevance. progress and pitfalls in the path towards an understanding of mycorrhizal functions in nature. In: van der Heijden MGA, Sanders IR (Eds) Mycorrhizal ecology. Springer Verlag, Heidelberg, Germany, pp 3-29

van Capelle C, Schrader S, Brunotte J (2012) Tillage-induced changes in the functional diversity of soil biota - a review with a focus on German data. Eur J Soil Biol 50:165-181

van der Heijden MGA, Bardgett RD, van Straalen NM (2008) The unseen majority: soil microbes as drivers of plant diversity and productivity in terrestrial ecosystems. Ecol Lett 11:296-310 
Vandenkoornhuyse P, Mahe S, Ineson P, Staddon P, Ostle N, Cliquet JB, Francez AJ, Fitter AH, Young JPW (2007) Active root-inhabiting microbes identified by rapid incorporation of plant derived carbon into RNA. Proc Natl Acad Sci USA 43:16970-16975

Verbruggen E, Röling WFM, Gamper HA, Kowalchuk GA, Verhoef HA, van der Heijden MGA (2010) Positive effects of organic farming on below-ground mutualists: large-scale comparison of mycorrhizal fungal communities in agricultural soils. New Phytol 186:968-979
Verbruggen E, Kiers ET, Bakelaar PNC, Röling WFM, van der Heijden MGA (2012) Soil communities from organically and conventionally managed fields provide different agro-ecosystem services. Plant Soil 350:4355

Wagg C, Jansa J, Stadler M, Schmid B, van der Heijden MGA (2011) Below ground fungal diversity drives above ground productivity. Ecol Lett 14:1001-1009

Whitman WB, Coleman DC, Wiebe WJ (1998) Prokaryotes: the unseen majority. PNAS 95:6578-6583 